\title{
ASSESSMENT OF THE ECOLOGICAL POTENTIAL OF HEAVILY MODIFIED WATER BODIES IN THE BASILICATA REGION, ITALY: CASE STUDY OF THE AGRI RIVER BASIN
}

\author{
FRANCESCO ARBIA ${ }^{1}$, LORENA DI GIUSEPPE ${ }^{1}$, RAFFAELE GIAMPIETRO ${ }^{1}$, \\ MICHELE GRECO $^{1,2^{*}}$, PATRIZIA MAURO ${ }^{1}$, GIOVANNI MARTINO ${ }^{2}$, ANNA MONTELLA $^{1}$, \\ GIOVANNI MUSSUTO ${ }^{1}$, ERIKA NAPOLI ${ }^{1} \&$ ANTONELLA SMALDONE $^{1}$ \\ ${ }^{1}$ Regional Environmental Research Foundation - FARBAS, Potenza, Italy \\ ${ }^{2}$ School of Engineering, University of Basilicata, Italy
}

\begin{abstract}
River morphology and ecosystem are macro-indicators of climate and land-use changes as well as human activities and land policies. In the last decades, knowledge of water resources, in terms of quality, quantity, prevention and control, has quickly increased - even for the availability of advanced methodologies and technologies both for monitoring and modelling fields. Nevertheless, the objective of a good ecological status of water bodies has not yet been reached due to human pressure which still induces long term impacts as well as direct or indirect physical constraints. In such a context, the European Water Framework Directive introduces the concepts of artificial water bodies (AWB) and heavily modified water bodies (HMWB) and states that in such cases good ecological potential must be reached while good ecological status is required only for natural water bodies (NWB). Further, the methodologies proposed for the AWB and HMWB need a wide set of parameters and measurements, which are not always systematically available, inducing further actions and analyses in order to evaluate the quality level of the water bodies. Moreover, the AWB or HMWB classification represents an opportunity to resize the measures addressed to achieve good ecological status both in terms of economic engagement and timing with relevant consequences on water resource planning and management. The paper deals with these issues and synthetically reports the work done on the whole Lucanian river network (Basilicata region, Southern Italy) and also presents the Agri River case study in order to classify, as best as possible, AWB, HMWB and NWB as well as to support survey planning.
\end{abstract}

Keywords: water framework directive, good ecological potential, good ecological status, heavily modified water bodies, artificial water bodies, natural water bodies.

\section{INTRODUCTION}

The main goal of the European Water Framework Directive issued by the European Commission [1] is to ensure water quality protection and improvement throughout the European Union (EU) by enforcing a common water resource management and control policy as well as by defining powerful strategies aimed to reduce pollution and natural resource overexploitation [2]. Such a Directive was promulgated in 2000 and defines the deadlines to reach the objective of a good ecological level of integrity for all the types of water bodies: rivers, lakes, transitional water, coastal water and groundwater [3]. In detail, the European water policy is addressed to achieve the strategic objective of good chemical status (GCS) as well as good ecological status (GES) of natural water bodies (NWB) and groundwater bodies (GWB). Otherwise, EU policy aims to reach good ecological potential (GEP) for the defined heavily modified water bodies (HMWB) and artificial water bodies (AWB) by 2015 or 2021

*ORCID: http://orcid.org/0000-0002-3986-7117 
or even 2027 under specific conditions. That is, in order to reach such a target, operative tools of integrated river basin management process have been created and promoted [4], [5].

In such a framework two main relevant aspects concerning the classification of NWB, HMWB as well as AWB arise. In fact, for NWB the GES is related to ensure only slight measures or actions in order to reach 'completely' or 'almost completely' undisturbed conditions. Otherwise, HMWB and/or AWB conditions might be identified and designated [6] before defining further restrictive measures. According to EC-WFD [1], hydromorphological conditions [7] as well as the uses of the water resources represent the basis to appoint water bodies as HMWB.

The water body designation as artificial or heavily modified occurs when, amongst other things, changes in the hydro-morphological characteristics would have significant adverse effects, for example, on flooding, navigation, hydro-power plants and so on. The target for such water bodies is to reach GEP, which corresponds to reduced environmental objectives [1], [8]. Moreover, the EC-WFD requires a severe reduction and prevention of the water quality deterioration for NWB, AWB and HMWB.

Furthermore, the classification must follow an intensive and well-structured monitoring plan requiring both chemical-physical and biological surveying in order to obtain an exhaustive framework concerning the effects and the impacts induced by natural and human activities.

The paper proposes the methodology applied in Basilicata (Southern Italy) and finalised to evaluate a possible classification as HMWB for several surface reaches in order to establish the real and coherent criticality scenario. In fact, the Basilicata region has six main rivers which were strongly affected by the construction of several reservoirs for agricultural and drinkwater purposes in the sixties. Hence, several dams and weirs were built during those decades, in which no environmental regulations were adopted according to the general global technical and social-economic culture. Of course, no legal actions can be applied at present, but because long-term effects still persist, structural interventions for hydro-morphological restoration in order to reach GEP are required. On the other hand, the age of this hydraulic work induces us to consider water bodies as natural because infrastructures are well integrated in the environmental landscape as well as a biodiversity producer. Furthermore, the general feeling of the local people about a dam built up in the sixties is to consider it as a lake with all the positive and negative related feedback. Besides, the upstream and downstream water body characteristics are still influenced by the dam/reservoir both in terms of hydraulics/hydrology and morphology as well as sedimentary dynamics. In such a case, even if the water discharge changes, the evaluation can always be performed by direct measurement or expeditive assessment [9], [10] and sustainable remediation system for sediment continuity might be proposed [11]. The local natural environment is compromised and only the concept of GEP can be reached.

\section{STUDY AREA - THE AGRI RIVER BASIN}

The proposed analysis has been applied to the whole of Lucanian river networks (Basilicata region, Southern Italy) but the present study refers only to the Agri River as a suitable example representing all the problems observed on the Lucanian river system. In detail, the study area consists of the Agri river basin. Agri river is one of the six major rivers of the Basilicata region, with a drainage basin area over $1715 \mathrm{~km}^{2}$ and varying morphology from mountainous and hilly, in the medium-high upstream part, to low hilly and flat, in the downstream portion. The hydrographic network is substantially ramified, presenting a main stream of about $113 \mathrm{~km}$ long, whose mountainous reach with NNW-SSE trend, crossing the 
intermontane depression of the Alta Val d'Agri and then assuming a fairly regular W-E trend reaching the Ionian coast of Lucania.

The average annual rainfall is quite homogeneous along the basin, following the distributions aligned to the NW-SE ridge with a reference value of 700-900 mm/yr.

From a geological point of view, the Agri River basin is characterized by a complex geological-structural order (Fig. 1) and, for this reason, the hydrogeology of a large part of the territory in that area is very complex (Fig. 2).

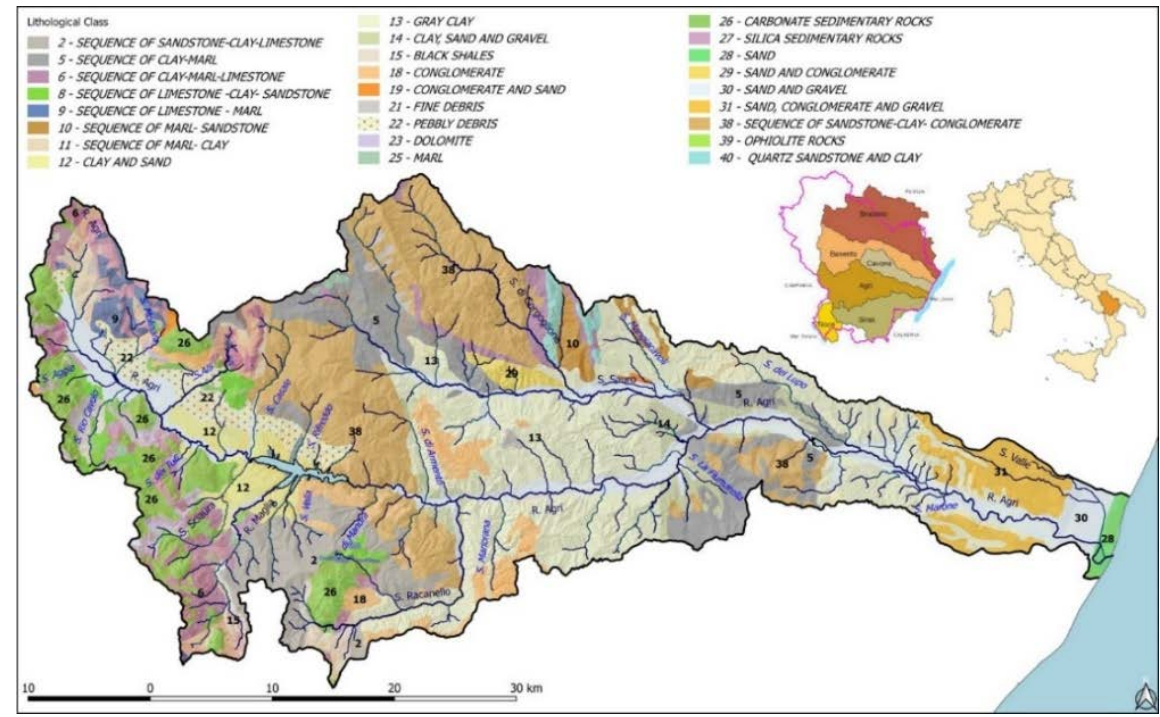

Figure 1: Geo-lithological classes and river network of Agri basin.

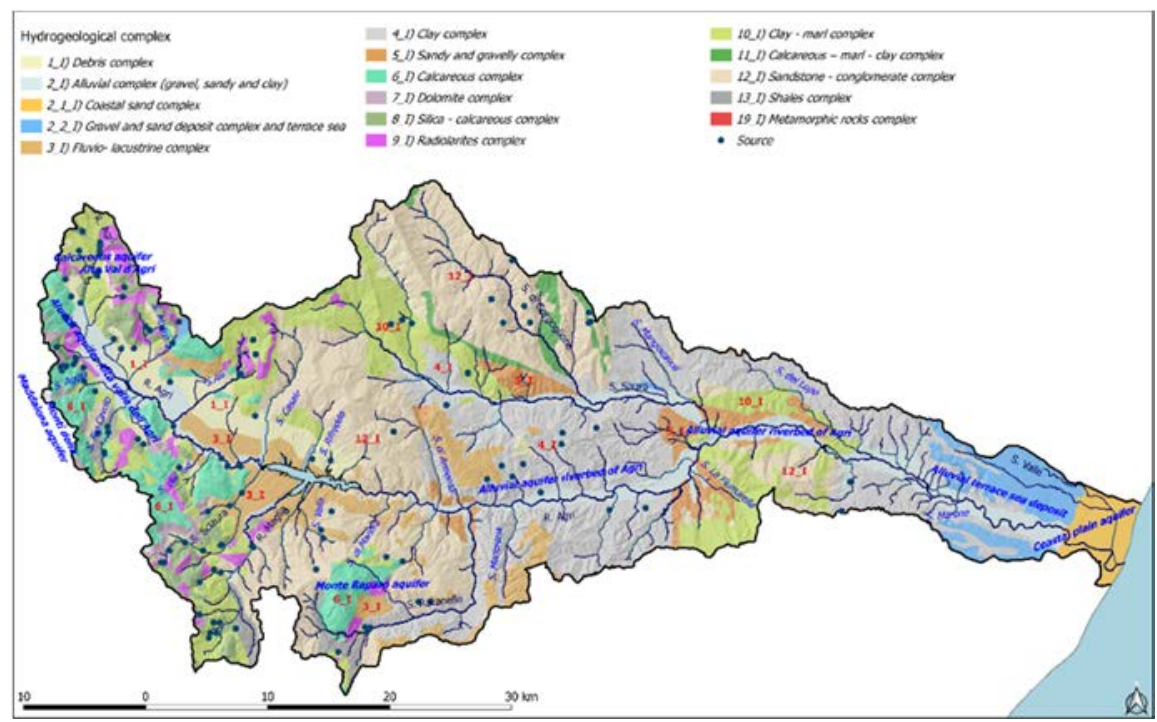

Figure 2: Hydrogeological system of the Agri basin. 
The carbonate rocks characterizing the main mountain ranges of the Alta Val d'Agri, in tectonic contact with clayey-marly units and flyschoids, represent the strategically most important aquifers in the basin.

In addition to the aforementioned hydrogeological domains, there are others that are less significant from the point of view of their water potential, but with a considerable interest and value. More specifically, it is worth highlighting:

a) the sandy-conglomeratic aquifers falling in the middle and lower portions of the basin;

b) the sandy and gravelly alluvial aquifers present in the down stream valley;

c) the sandy aquifer falling into the Coastal Plain.

Furthermore, the Alta Val d'Agri area is characterized by calcareous and calcareousdolomitic succession mesozoic platforms, which occupy a large part of the north-western basin and by meso-cenozoic succession of deep basin, originating from the deformation of a dominion oceanic tetidus, and from Lagonegro-type basin units, covered in discordance by myocenic synoptic clastic formations.

Moreover, most of the valley area is characterized by deposits of fluvio-lacustrine basin generated by a system of plio-quaternary faults having preferential directions $\mathrm{N} 120^{\circ} \pm 10^{\circ}$. Recent studies highlight a transversal structure of the basin similar to an irregular graben, asymmetrical towards the north-eastern margin.

Longitudinally, the basin consists of three main depocenters separated by two structural high-oriented NE-SW. The meso-cenozoic tectonic units, present in this area, are attributed to different original contiguous paleogeographic domains.

\section{MORPHOLOGICAL QUALITY INDEX FOR THE AGRI RIVER}

In Italy, the EC-WFD has been adopted through the introduction of Morphological Quality Index method (MQI), described in detail in reference guide IDRAIM [12]. It is quite important to point out that the Italian legislative system adopts MQI as an official methodology for the classification of the biological, chemical and hydro-morphological status of water bodies.

The methodology is based on evaluating the deviation from a given reference morphological state of each water body. Further, the approach takes into account the temporal context, in terms of trends of 'trajectory' and morphology of the fluvial system in order to understand its current conditions.

The first phase of MQI evaluation procedure provides a general setting of the physical conditions of the river and carries on an initial classification in relatively homogeneous reaches based on physiography, channel confinement, channel pattern, river typology and artificial interventions.

Further, the second phase consists of real measurement of MQI for all of the homogeneous selected reaches, in order to classify the present morphological state according to three different components:

a) morphological functionality: based on the observation of processes in the present conditions;

b) artificiality: in which frequency and impact of artificial interventions are evaluated;

c) morphological channel changes: recent morphological variations (referring to the planimetric changes in the last 50-60 years) are examined. 
These parameters of functionality, artificiality and morphological channel changes are investigated by using specific assessment procedures, based on schematic reports, which allow us to analyse the different conditions constraining the status of the stream.

For this reason, a number of indicators are used, providing both qualitative and quantitative evaluation of variables and schematic reports are differentiated for various aspects, depending on river typologies (confined channels or/and semi-unconfined channels) in order to provide an exhaustive morphological characteristic value. However, the MQI methodology is not suitable for assessing changes in morphological quality of small channels, and it is not applicable to artificial water bodies, lakes, or reservoirs.

The main idea deals with the measurement of the deviation between the morphological conditions of the considered stream and undisturbed conditions which represent the optimal status. In detail, the following reference classes are considered:

- class A: undisturbed conditions or negligible alterations score 0;

- class B: intermediate alterations scores from 2 to 5;

- class C: very altered conditions scores from 6 to 12 .

Thus, the total deviation $S_{\text {tot }}$ from not-altered conditions is calculated as the sum of the scores assigned to all indicators and it provides an assessment of the deterioration of the reaches compared to their natural conditions.

This value can be normalized with respect to $S_{\max }$, that is the maximum score that could be obtained once all indicators assume the maximum possible score. Further, the Morphological Alteration Index (MAI) represents the normalized assessment of the morphological alteration of the considered water body and is obtained by the ratio [12]:

$$
M A I=S_{\text {tot }} / S_{\max }
$$

The Morphological Quality Index (MQI) is then defined as [12]:

$$
M Q I=1-M A I
$$

Such an index assumes value 1 in the case of reference conditions (corresponding to totally natural condition) and value 0 in case of maximum alteration of the water body. All other conditions fall in between these limits. Moreover, different classes of morphological quality are defined as reported in Table 1.

Table 1: Morphological Quality Index classification.

\begin{tabular}{|c|c|c|c|c|c|}
\hline MQI & $0.0 \leq \mathrm{MQI}<0.3$ & $0.3 \leq \mathrm{MQI}<0.5$ & $0.5 \leq \mathrm{MQI}<0.7$ & $0.7 \leq \mathrm{MQI}<0.85$ & $0.85 \leq \mathrm{MQI}<1.0$ \\
\hline $\begin{array}{c}\text { Quality } \\
\text { class }\end{array}$ & Bad status & Poor status & $\begin{array}{c}\text { Moderate } \\
\text { status }\end{array}$ & Good status & High status \\
\hline
\end{tabular}

Fig. 3 shows the resulting MQI classification for the Agri River drainage network referring to all the water bodies selected in the basin and codified through the Water Information System for Europe (https://water.europa.eu/). The data used for the evaluation refer to an intensive measurement campaign carried out in 2016-2017 by the Regional Environmental Protection Agency (ARPAB). 


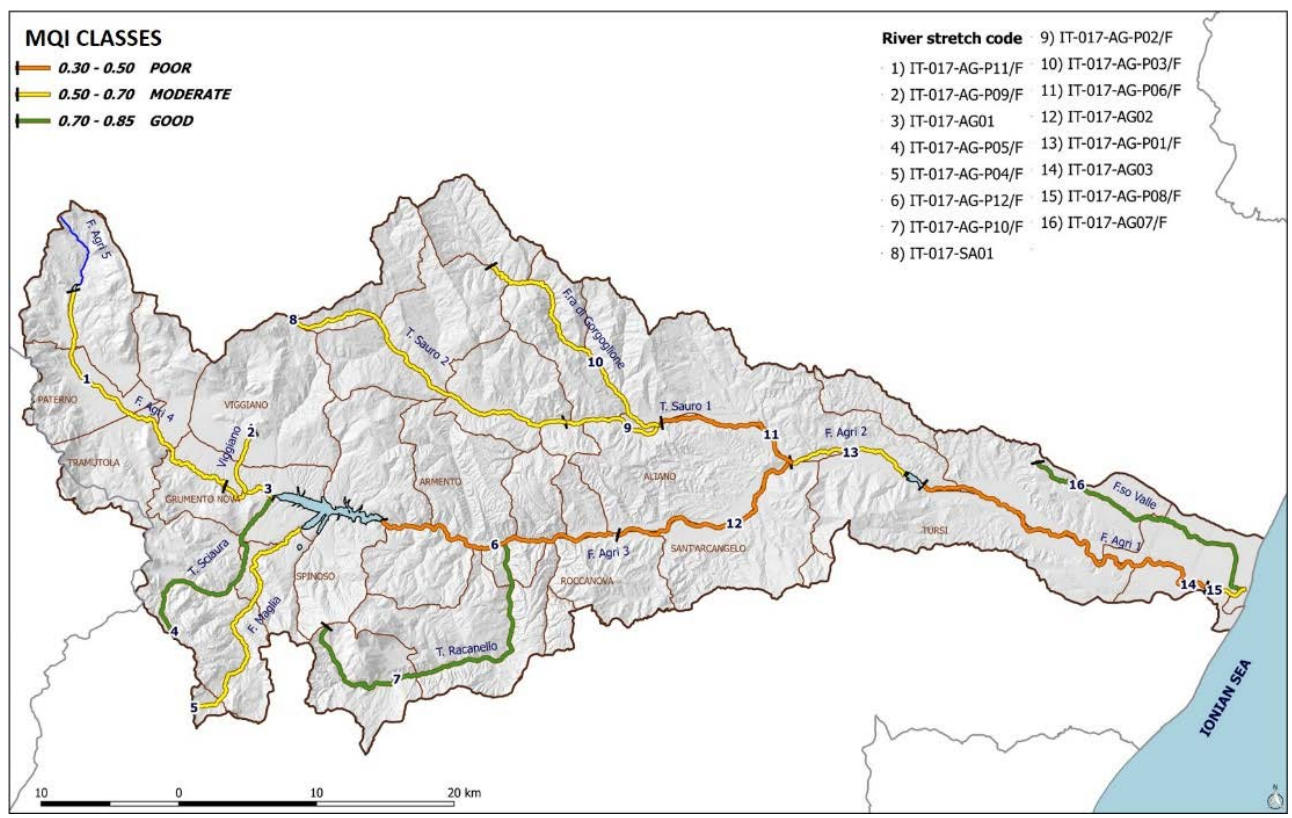

Figure 3: Morphological Quality Index classification for the Agri River basin.

\section{ASSESSMENT OF ECOLOGICAL POTENTIAL OF HMWB}

The methodology, described in the IDRAIM manual [12], is divided into two phases and reflects the contents of the European Guidance document [6]:

a) 'PHASE 1' is defined as the 'Preliminary Identification' procedure: this phase involves the identification of water bodies that provisionally could be indicated as HMWB basing on technical, hydro-morphological and ecological evaluations;

b) 'PHASE 2' is defined as the 'Designation' procedure: in this phase the HMWB are definitively designated and the effective recognition requires both technical and socio-economic assessments and complex political choices.

In detail, the morphologically homogeneous reaches, characterized by high and significant hydro-morphological alterations, are preliminarily identified as HMWB, through cases of attribution, defined by the National Institute for Environmental Protection and Research (ISPRA) [12] and listed in Table 2. For each considered water body, accurate analyses are performed in order to verify the occurrence of at least one of the listed significant hydromorphological alteration cases.

In the case of Agri River, 16 water bodies have been assumed as representative of the whole basin and have been surveyed and monitored performing biological and chemical analyses (Fig. 4) providing a detailed monography of the main stream and all possible significant hydro-morphological alterations affecting the system.

The general and clear framework of the system of water bodies belonging to the Agri River network is obtained by combining the sets of biological and chemical analyses and monitoring, with the results of surveys addressed to reveal high and significant hydro- 
Table 2: List of reference for high and significant hydro-morphological alteration cases.

\begin{tabular}{|c|c|}
\hline 1 & $\begin{array}{l}\text { Transversal structures (including bed sills and ramps) with density }>1 \text { every } n \text {, where } \\
n=100 \mathrm{~m} \text { in mountain landscape and } n=500 \mathrm{~m} \text { in flat/hilly area }\end{array}$ \\
\hline 2 & Bank protection and/or levees at contact with most of the water body $(>66 \%)$ \\
\hline 3 & Presence of bed revetments for most of the water body \\
\hline 4 & $\begin{array}{l}\text { Presence of a dam (or check dams and weirs) at the upstream boundary of the water } \\
\text { body }\end{array}$ \\
\hline 5 & $\begin{array}{l}\text { Presence of transversal structures (check dams or weirs) inside the water body or at } \\
\text { the downstream boundary which cause high alteration of hydrodynamic conditions } \\
\text { and artificial lentic reaches }\end{array}$ \\
\hline 6 & $\begin{array}{l}\text { High alteration of hydrodynamic conditions in the reaches (significant decrease or } \\
\text { increase of flow) }\end{array}$ \\
\hline 7 & Alteration of hydrodynamic characteristic of water body due to hydropeaking \\
\hline 8 & $\begin{array}{l}\text { Combination of } \\
1-7, \text { but the con }\end{array}$ \\
\hline
\end{tabular}

\begin{tabular}{|c|c|c|c|c|c|c|c|c|c|c|c|}
\hline WISE Code & $\begin{array}{l}\text { Macro } \\
\text { benthos }\end{array}$ & $\begin{array}{l}\text { Macro } \\
\text { phyte }\end{array}$ & Diatoms & Fish & $\begin{array}{l}\text { Chem/ } \\
\text { Phys }\end{array}$ & WISE Code & $\begin{array}{l}\text { Macro } \\
\text { benthos }\end{array}$ & $\begin{array}{l}\text { Macro } \\
\text { phyte }\end{array}$ & Diatoms & Fish & $\begin{array}{l}\text { Chem/ } \\
\text { Phys }\end{array}$ \\
\hline IT-017-AG-P11/F & eses & als & 2 & 3 & $\Delta$ & IT-017-SA01 & Bes? & n.a & n.a & n.a & $\Delta$ \\
\hline IT-017-AG-P09/F & Ges? & 25 & n.a & 5 & $\Delta$ & IT-017-AG-P02/F & Bs: & n.a & $=2$ & i & $\Delta$ \\
\hline IT-017-AG01 & Ges? & 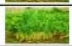 & $2 \leq$ & n.a & $\Delta$ & IT-017-AG-P03/F & Ses? & n.a & $2 \leq$ & 3 & $\Delta$ \\
\hline IT-017-AG-P05/F & $55^{2} 3$ & Sis & 25 & 8 & $\Delta$ & IT-017-AG-P06/F & n.a & n.a & 25 & 8 & $\Delta$ \\
\hline IT-017-AG-P04/F & हू? & n.a & n.a & 8 & $\Leftrightarrow$ & IT-017-AG-P01/F & Cong & n.a & n.a & 8 & $\Delta$ \\
\hline IT-017-AG-P12/F & Ases & n.a & n.a & 8 & $\Delta$ & IT-017-A G03 & n.a & n.a & $2 \leq$ & n.a & $\Delta$ \\
\hline IT-017-AG-P10/F & n.a & n.a & n.a & 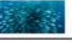 & $\Delta$ & IT-017-AG-P08/F & n.a & n.a & n.a & 6 & $\Delta$ \\
\hline IT-017-AG02 & Sos? & n.a & 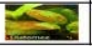 & n.a & $\Delta$ & IT-017-AG-P07/F & n.a & n.a & n.a & 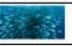 & $\Delta$ \\
\hline
\end{tabular}

Figure 4: Framework of biological and chemical analyses performed on the water bodies.

morphological alterations. Figs 5 and 6 show the ecological status and the ecological potential maps for the Agri River respectively. Table 3 reports a comparison outlining in which water body the high and significant hydro-morphological alterations occur and the relative ecological status, as inferred through the bio-chemical analyses and the ecological potential as well.

The operative results are quite interesting, showing an overall positive picture of the Agri River system. In fact, the assessment of the ecological status of water bodies seems to provide a crucial and critical scenario, due to the relevant percentage of water bodies in moderate ecological status that is close to $40 \%$ of the total water bodies. On the other hand, taking into account the possibility to classify some of the water bodies as HMWB, the total amount of water bodies in moderate ecological status sensitively decreases to $16 \%$ and the general status increases the quality triggering the good/high ecological potential.

Such results have an interesting and relevant feedback on the basin action plan addressing the measures and interventions to be implemented in order to reach the Good Ecological Status (GES) for those low-quality water bodies. That is, the Agri River has a very good ecological potential with a positive feedback for the whole system. Furthermore, the quantitative effect of the aforementioned results deals with the effectiveness of the 


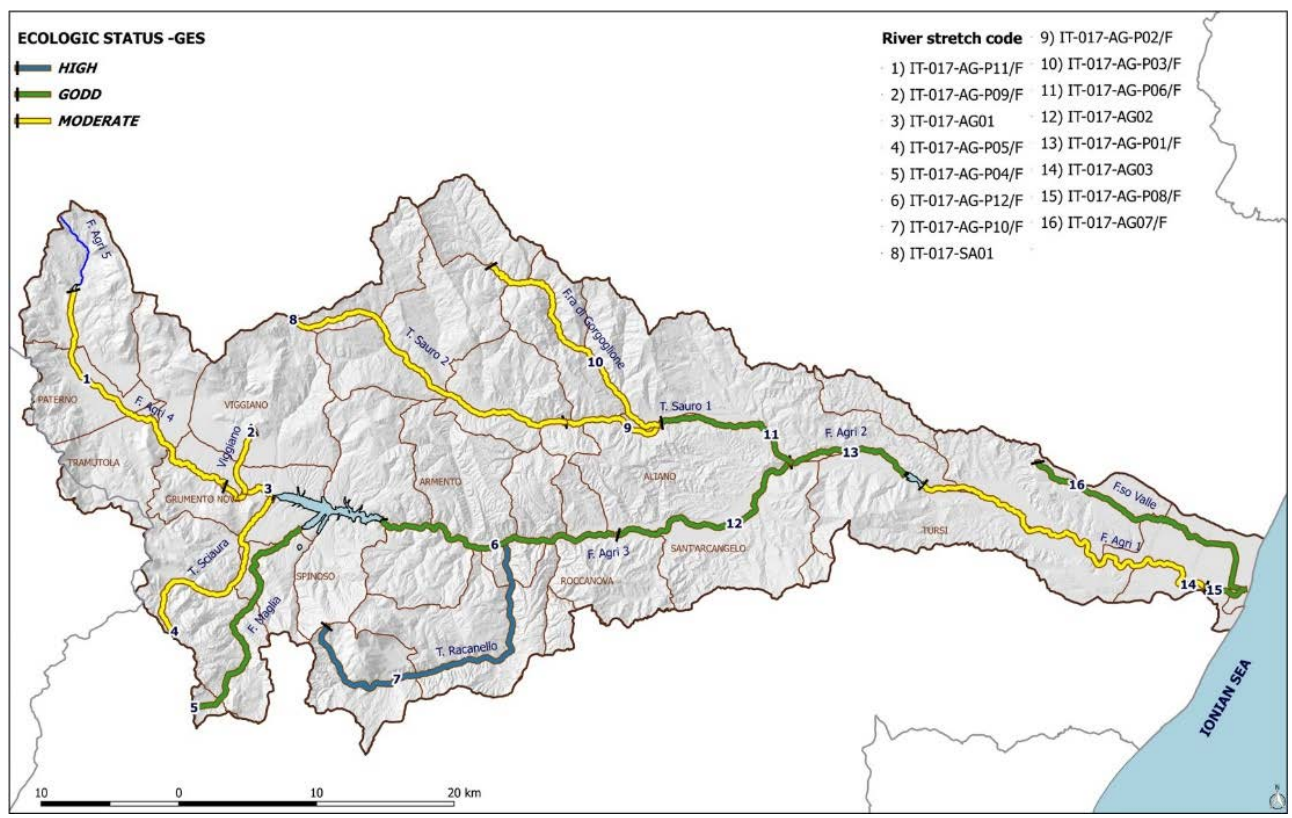

Figure 5: Ecological status of Agri River water bodies.

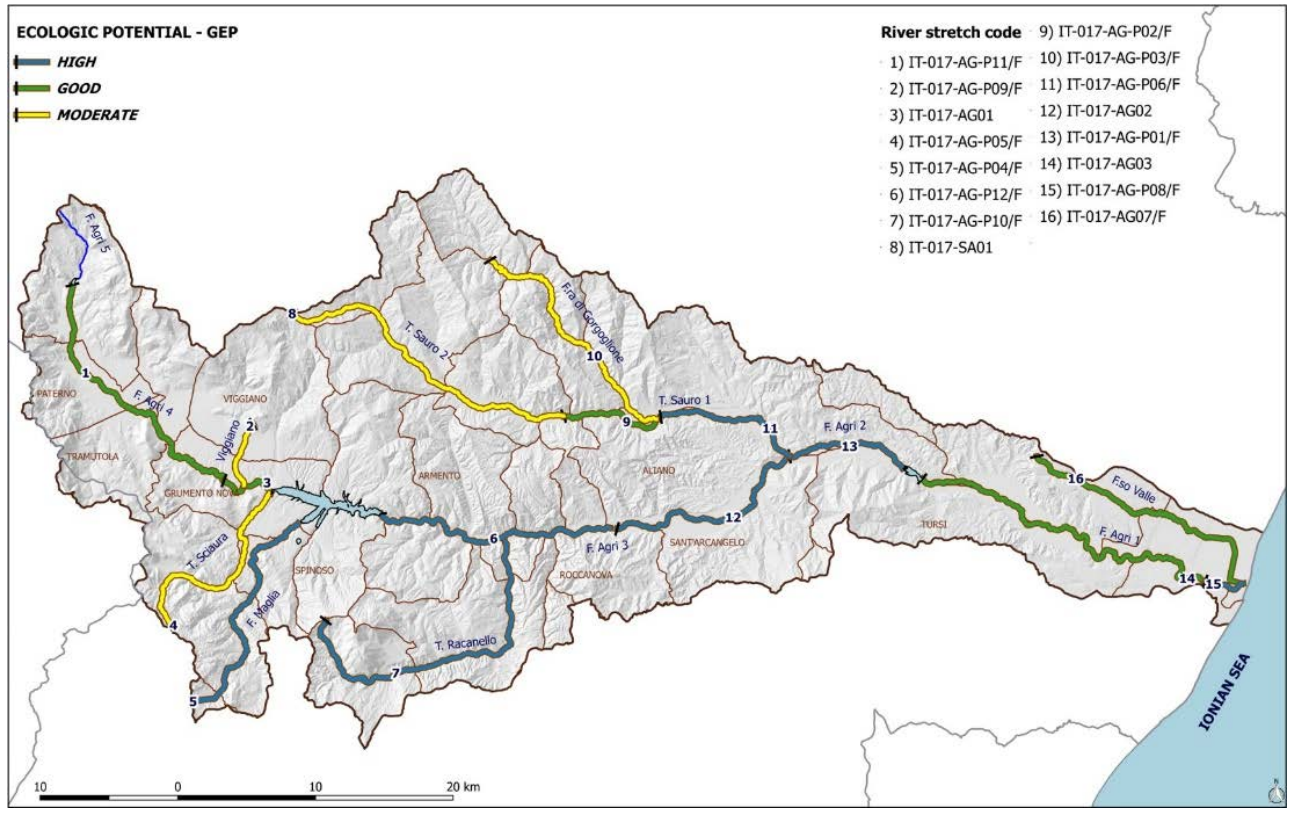

Figure 6: Ecological potential of Agri River water bodies. 
Table 3: General framework comparing the ecological status, provisional identification of HMWB and the ecological potential for the Agri river system.

\begin{tabular}{|l|c|c|c|}
\hline WISE code & $\begin{array}{c}\text { Ecological } \\
\text { status }\end{array}$ & $\begin{array}{c}\text { Provisional } \\
\text { identified HMWB }\end{array}$ & $\begin{array}{c}\text { Ecological } \\
\text { potential }\end{array}$ \\
\hline IT-017-AG-P11/F & MODERATE & HMWB & GOOD \\
\hline IT-017-AG-P09/F & MODERATE & NO HMWB & MODERATE \\
\hline IT-017-AG01 & MODERATE & HMWB & GOOD \\
\hline IT-017-AG-P05/F & MODERATE & NO HMWB & MODERATE \\
\hline IT-017-AG-P04/F & GOOD & HMWB & HIGH \\
\hline IT-017-AG-P12/F & GOOD & HMWB & HIGH \\
\hline IT-017-AG-P10/F & HIGH & NO HMWB & HIGH \\
\hline IT-017-AG02 & GOOD & HMWB & HIGH \\
\hline IT-017-SA01 & MODERATE & NO HMWB & MODERATE \\
\hline IT-017-AG-P02/F & MODERATE & HMWB & GOOD \\
\hline IT-017-AG-P03/F & MODERATE & NO HMWB & MODERATE \\
\hline IT-017-AG-P06/F & GOOD & HMWB & HIGH \\
\hline IT-017-AG-P01/F & GOOD & HMWB & HIGH \\
\hline IT-017-AG03 & MODERATE & HMWB & GOOD \\
\hline IT_017_AG_P08/F & GOOD & HMWB & HIGH \\
\hline IT-017-AG-P07/F & GOOD & NO HMWB & GOOD \\
\hline
\end{tabular}

sustainable policy developed in the last few years on the water resources and the relevant reduction of the amount of investments to be employed to resolve problems as well as to maintain such a good status of the river system. That is, the AWB or HMWB classification represents an operative tool to review the measures addressed to achieve the good ecological status in terms of economic engagement and scheduling augmenting the positive effects on water resource planning and management.

The extension of such approach to all the Lucanian rivers allow us to define a good scenario supporting the related water resource policies to be implemented for maintaining and further increasing the ecological status.

\section{CONCLUSIONS}

The macro-components of river morphology and ecological system are sensitive indicators of natural and human alterations due to climate and land-use changes and management as well as territorial policies.

The European Water Framework Directive establishes common policies in the field of water resource management and control able to ensure the objective of water quality protection in the EU Countries because water is a heritage which must be protected, defended and treated as such. Thus, the Directive aims to achieve the goal of a good ecological level of integrity even for fresh water, groundwater, transitional water and marine water as well.

Further, the WFD introduces the concepts of artificial water bodies (AWB) and heavily modified water bodies (HMWB) and states that in such cases good ecological potential (GEP) must be reached while good ecological status (GES) is required only for natural water bodies (NWB). Moreover, the increasing knowledge in advanced methodologies and technologies for both monitoring and modelling has strongly augmented the institutional capability for water resources management, in terms of quality, quantity, prevention and control. In such a context, the paper deals with the operative implementation of the methodology adopted for 
the Lucanian rivers and describes the Agri River case study in order to propose the current surface water classification using heavily modified water bodies as reference.

The obtained results show an overall positive vision of the river drainage network which rates from moderate level to high level of ecological potential. Hence, such results highlight not only the effectiveness of the employed local water resource policies but very interesting prospective effects on the forthcoming regional water basin management aimed to completely ensure EC-WFD objectives.

Finally, the AWB or HMWB classification represents an opportunity to resize the measures addressed to achieve the good ecological status both in terms of economic engagement and timing with relevant effects on water resource planning and management.

\section{ACKNOWLEDGEMENTS}

This work has been granted by Regione Basilicata - DGR 1490/2014 - Project "INDICARE - Indicizzazione delle criticità ambientali regionali della Basilicata" and carried out by the Regional Environmental Research Foundation (FARBAS).

\section{REFERENCES}

[1] EC-WFD, Directive 2000/60/EC of the European Parliament and of the Council of 23 October 2000 establishing a framework for Community action in the field of water policy. European Water Framework Directive. Official Journal of the European Communities, L 327/1, 2000.

[2] Koenig, F., Quick, I. \& Vollmer S., Defining quantitative morphological changes in large rivers for a sustainable and effective sediment management applied to the River Elbe, Germany. Proceedings of the Tenth International Conference on Hydroscience \& Engineering, pp. 4-8, 2012.

[3] Cron, N., Quick, I. \& Zumbroich, T., Assessing and predicting the hydromorphological and ecological quality of federal waterways in Germany: development of a methodological framework. Hydrobiologia, 2015.

DOI: $10.1007 / \mathrm{s} 10750-015-2484-\mathrm{x} 2015$.

[4] Weiß, A., Matouskova, M. \& Matschullat, J., Hydromorphological assessment within the EU-Water Framework Directive - trans-boundary cooperation and application to different water basins. Hydrobiologia, 603(1), pp. 53-72, 2008.

[5] Raven, P.J., Holmes, N.T.H., Charrier, P., Dawson, F.H., Naura, M. \& Boon, P.J., Towards a harmonized approach for hydromorphological assessment of rivers in Europe: a qualitative comparison of three survey methods. Aquatic Conservation: Marine and Freshwater Ecosystems, 12(4), pp. 405-424, 2002.

[6] CIS, Guidance document no. 4 - Identification and Designation of Heavily Modified and Artificial Water Bodies. Produced by working Group 2.2 - HMWB. CIS Common Implementation Strategy for the Water Framework Directive (2000/60/EC), Luxemburg, 2003.

[7] Benjankar, R., Koenig, F. \& Tonina, D., Comparison of hydromorphological assessment methods: application to the Boise River, USA. Journal of Hydrology, 492 , 128-138, 2013.

[8] CIS, Guidance document n. 13 - Overall Approach to the Classification of Ecological Status and Ecological Potential. Produced by working Group 2A. CIS - Common Implementation Strategy for the Water Framework Directive (2000/60/EC), Luxemburg, 2005. 
[9] Mirauda, D., Greco. M. \& Moscarelli, P., Practical method for flow velocity measurements in fluvial sections. WIT Transactions on Ecology and the Environment, 146, pp. 355-366, 2011.

[10] Greco, M. \& Martino, G., 1-D versus 2-D entropy velocity law for water discharge assessment in a rough ditch. Entropy 2018, 20(9), p. 638, 2018.

[11] Carone, M.T., Greco, M. \& Molino, B., A sediment-filter ecosystem for reservoir rehabilitation. Ecological Engineering, 26(2), pp. 182-189, 2006.

[12] Rinaldi M., Surian N., Comiti F. \& Bussettini M., IDRAIM, Sistema di valutazione idromorfologica, analisi e monitoraggio dei corsi d'acqua, ISPRA, Manuali e Linee Guida 113/2014, Roma, 2014. 